\title{
A FORMAL ANALYSIS OF THE FRENCH TEMPORAL CONNECTIVE alors
}

\author{
MYRIAM BRAS, ANNE LE DRAOULEC \\ AN D NICHOLAS ASHER \\ University of Toulouse
}

A B S T R A C T

This paper presents an analysis of the French adverbial alors (then, at that time, so). Among the linguistic markers that establish a temporal relation between the eventualities introduced by two clauses, we define as temporal connectives those that introduce at the same time some sort of discourse relation. We argue that alors can be such a connective. Within the framework of Segmented Discourse Representation Theory, our investigation concerning the discourse information conveyed by sentence initial alors reveals at least three sorts of relations close to the Result relation of SDRT. Alors alone conveys a weak causal relation, which we formalize using Lewis' counterfactual, and encode in the discourse relation Weak-Result. We distinguish it from Strong-Result, which is inferred when lexical or other contextual information suggests a causal, discursive link. We also show that alors can, when Weak-Result is blocked, suggest an inferential relation, which we express using the weak conditional already present in SDRT.

Et qu'est-ce que l'autre lui raconte ! Qu'il devrait ajouter un bouton! Oui ! Un bouton à son pardessus ! à son pardessus! alors. alors l'autobus est arrivé. Alors j'ai monté dedans. Alors j'ai vu un citoyen qui m'a saisi l'oeil. Alors j'ai vu son long cou et j'ai vu la tresse qu'il $\mathrm{y}$ avait autour de son chapeau. Alors il s'est mis à pester contre son voisin [...] RAYMOND QUENEAU, Exercices de style, 1947)

\section{[1] INTRODUCTION}

This paper presents an analysis of the French temporal connective alors (generally translated in English by then, at that time, so). It is part of a broader project aimed to provide a systematic analysis of French temporal connectives within the formal framework of Segmented Discourse Representation Theory (Asher 1993; Asher and Lascarides 2003). We define as a temporal connective any adverb that expresses 
a temporal (or aspectuo-temporal) relation between two eventualities and, at the same time, implies a logico-pragmatic relation between the two utterances in which the eventualities are described (Le Draoulec and Bras 2006). In other words, temporal connectives are adverbs that play a role at the discourse level in introducing discourse relations.

In previous work, we showed that puis is just such a connective. Its role in SDRT is to impose a relation of Narration (whose semantics includes a temporal relation of succession) and to block causal relations like Result (cf. Bras et al. 2001, Borillo et al. 2004). We argue here that alors can also be such a temporal connective under specific conditions.

Much work has been done on alors (cf. inter alia Jayez 1981, 1988b,a, Franckel 1987, Gerecht 1987, Hybertie 1996, Reyle 1998). Our starting point is the work of Hybertie (1996), partly based on the analyses of Jayez, Franckel and Gerecht. Hybertie distinguishes three major uses of alors in assertions ${ }^{1}$ :

TEMPORAL USES:

with only a temporal link between the eventualities:

(1) J'ai rencontré Pierre en 1987. J'étais alors une jeune étudiante. ${ }^{2}$ 'I met Pierre in 1987. I was alors a young student.'

with a temporal link and a dependency link (that we'll explain below):

(2) Je suis allée jusqu'à la place du village, alors je l'ai vu arriver. 'I walked up to the village square. Alors I saw him arrive.'

CONSEQUENTIAL USES:

between eventualities:

(3) J'étais pressé, alors j'ai pris le sens interdit. 'I was in a hurry. Alors I took the one way street the wrong way.'

(4) Olivier a fait tomber la carafe. Alors elle s'est cassée. ${ }^{3}$ 'Oliver dropped the carafe. Alors it broke.'

between two cognitive states in an inferential process:

(5) Les volets sont fermés, alors ils sont partis.' 'The shutters are closed, alors they have left.' (I see that the shutters are closed, so I infer that they must have

[1] The cases in which alors is associated with an interrogative or an exclamative intonation are left aside.

[2] All the examples below but (4) and (6) are taken from (Hybertie 1996). In the English glosses, we prefer not to choose a translation of alors, so as not to blur the problem.

[3] In (4), contrary to (2), alors could be replaced by donc. 
left).

(6) Ce nombre est égal à 4. Alors il est pair. (Jayez 1988b, 158)

'This number is equal to 4 . Alors it is even.'

and OTHER USES where alors is a kind of "structuration" marker: with only a temporal link between the eventualities:

(7) Oui bonsoir j'habite en moselle, alors actuellement il existe une loi sur le travail à mi-temps pour les femmes [...]

'Yes, good evening. I live in Moselle county, alors at present there is a law concerning part time work for women [...]'

Le Draoulec and Bras (2007) analyze the uses of alors that Hybertie classifies as "temporal uses". Restricting their analysis to uses of alors that involve only events, they showed that the temporal link conveyed by alors is associated with a rhetorical relation between constituents only when alors is in clause initial position, as in example (2). This rhetorical relation expresses a dependency link that has been described by Hybertie as follows: the event expressed by the first constituent is a "condition for the realization" of the event described by the second constituent. In these cases only, alors meets the requirements of a temporal connective in the sense defined above.

When alors is in a clause internal or final position, its role is merely that of a temporal anaphoric adverb conveying a temporal relation (with only possible semantic effects of consequentiality when it is in internal position), as in example (1).

Moreover, as far as the temporal relation between the events is concerned, the temporal value itself depends on the sentential position: clause initial alors gives rise to a relation of temporal succession between the events, as in (2); clause internal or final alors denotes a temporal relation of concomitance or coincidence as in (1).

In this paper we consider the uses of alors when it is a temporal connective, leaving aside its temporal adverbial uses (examples such as (1) are thus excluded). We provide a formal analysis of the "temporal uses", and we extend the analysis to the "consequential uses" in the classification of Hybertie above.

Some of these consequential cases - those linking eventualities - have a temporal value that leads us to group them together with the temporal cases. In this enlarged set of temporal uses of alors, we have developed a new classification on the basis of the discursive link at issue: the link either provides a dependency link like the one described by Hybertie, or a cause-consequence relation. Alors as a temporal connective will be analysed in section 3 , where we investigate which discourse relations are able to account for the different types of dependency/causality associated with alors. 
The restriction to clauses describing events is still in force in this analysis states are left for future research. Thus, we will exclude examples such as (3). For the consequential cases listed above involving cognitive states such as (5) and (6), we will only sketch lines of analyses for cases where events are involved. These cases will form a new class and will be analysed in section 4 where we deal with alors as a "logical connective".

Finally, the "structuration marker" cases such as (7) won't be taken into account.

\section{[2] FRAMEWORK FOR FORMALIZATION：SDRT}

\section{[2.1] Overwiew of SDRT}

SDRT is a formal theory of the semantics-pragmatics interface. It is an extension of Kamp's Discourse Representation Theory (Kamp and Reyle 1993) that takes discourse relations into account. We will give a brief outline of SDRT here. The reader is invited to refer to (Asher and Lascarides 2003) for a thorough presentation. In SDRT, a discourse is represented by an SDRS (Segmented Discourse Representation Structure). It is a recursive structure consisting of labelled elementary DRSs (i.e., Discourse Representation Structures, as described by DRT) representing a single clause and labelled sub-SDRSs linked together by Discourse Relations, such as Narration, Elaboration, Background, Continuation, Result, Contrast, Explanation...

These elementary DRSs and the sub-SDRSs corresponding to complex discourse segments are the constituents of the SDRS representing the discourse. The elementary constituents describe eventualities, i.e. events or states.

Labels are discourse referents. They are used to distinguish different occurrences of constituents, since each occurrence of a constituent in a discourse structure will be affected differently, at least in principle, by the discourse context. The labels for the constituents are essential because a given proposition or semantic content may have many different uses in different discourse contexts ${ }^{4}$. To keep the whole theory within a first order setting, discourse relations take labels as arguments. In our formulation of the axioms for inferring and interpreting the various discourse relations linking constituents, we will use Greek letters $(\alpha, \beta$, ...) as variables to represent labels, $K_{\alpha}$ to represent the constituent labelled with $\alpha$, and $e_{\alpha}$ to represent the main eventuality (event or state) described by $K_{\alpha}$.

To construct an SDRS for a discourse, we need to add considerably to the construction algorithm posited for DRSs. SDRT defines a "Glue Logic" and an "Update Function" that together determine a new SDRS for a given SDRS $K_{0}$ representing the context (the discourse already processed) and a new constituent $K_{\alpha}$ representing the information to be integrated into that context. The Glue Logic ex-

[4] A label can be seen as a kind of speech act discourse referent. 
ploits the framework of "Commonsense Entailment" (Asher and Morreau 1991), a logic that exploits both monotonic $(\rightarrow)$ and non-monotonic $(>)$ conditionals. In Commonsense Entailment (CE), $\varphi>\psi$ means "if $\varphi$ then normally $\psi$ ". From $\varphi>$ $\psi$ and $\varphi$, CE entails $\psi$ "by default", that is, defeasibly, in the absence of further information regarding the truth value of $\psi^{5}$.

Asher and Lascarides (2003) analyze the Glue Logic as a description logic that makes extensive use of underspecification. We will adopt the convention used in the Glue Logic of adding a third argument to two place predicates like discourse relation predicates: a formula of the form $R(\alpha, \beta, \lambda)$ is to be understood as a constraint on the third argument $\lambda$, which is the label of the smallest SDRS containing the formula linking the label $\alpha$ to the label $\beta$ via the discourse relation $R$.

As far as the inferential tasks are concerned, the Glue Logic contains:

(i) definitions characterizing which constituents in the contextually given SDRS are open for attaching the current constituent $\beta$,

(ii) axioms detailing what discourse relations may be inferred, on the basis of a variety of linguistic and common knowledge clues, in order to actualize the attachment of $\beta$ to some open constituent $\alpha$ of the contextually given SDRS.

SDRT also contains axioms specifying the semantic effects of the discourse relations, which can be considered as meaning postulates. We will give examples of such axioms in the next section.

The Update Function is in charge of integrating the discourse relations the Glue Logic infers and its choice of attachment sites within the contextually given SDRS representing the structure of the discourse processed so far. This integration may also involve the resolution of underspecifications (e.g., anaphora and ellipses).

SDRT distinguishes coordinating relations from subordinating ones. Explanation and Elaboration are examples of subordinating relations, while Narration is a coordinating relation. Subordinating and coordinating relations affect the Update Function differently. Only subordinating relations may introduce complex SDRSs, in other words, the Update Function may gather several SDRSs into a new complex SDRS only if these constituents are attached to the same site with the same subordinating relation. Asher and Vieu (2005) provide criteria within SDRT for coordinating and subordinating relations. They also postulate that some relations like Result, though in most cases a coordinating discourse relation, may in certain contexts be subordinating instead.

[5] From $\varphi>\psi, \varphi$ and $\neg \psi$, CE no longer entails $\psi$, but $\neg \psi$. From $\varphi>\psi, \zeta>\neg \psi, \varphi \rightarrow \zeta, \varphi$ and $\zeta, \psi$ (and not $\neg \psi$ ) is inferred (Penguin principle). From $\varphi>\psi, \zeta>\neg \psi, \varphi$ and $\zeta$, if $\varphi$ and $\zeta$ are logically independent, CE cannot conclude $\psi$ nor $\neg \psi$ (Nixon Diamond). 
In SDRT several discourse relations may simultaneously link the same two constituents, thus distinguishing SDRT from other discourse approaches, notably RST (Mann and Thompson 1988). SDRT also allows for multiple "superordinate" parents of a constituent, which means that SDRSs must be graphs and cannot be represented completely faithfully as trees. ${ }^{6}$

In the following, we only present the discourse relations needed to describe the discourse contribution of temporal connectives such as puis and alors: the SDRT relations Narration and Result.

\section{[2.2] The Discourse Relation of Narration}

Narration is a relation which is based on the Gricean pragmatic maxim of manner "be orderly". When two clauses are linked by Narration, they describe in sequence two successive events "of the same story".

Narration can be non-monotonically inferred if the two clauses to be related contain clues indicating that their main eventualities are of types that may belong to 'the same story'. This "condition" on the types of the eventualities described by the clauses is formalized by the predicate Occasion, which serves as a triggering condition to the non-monotonical inference of Narration in the following axiom, where $\lambda$ represents the smallest constituent that will end up containing the formula that links $\alpha$ and $\beta$ once the SDRS for the discourse is constructed and fully specified:

\section{AXIOM NARRATION$$
(?(\alpha, \beta, \lambda) \wedge \operatorname{Occasion}(\alpha, \beta))>\operatorname{Narration}(\alpha, \beta, \lambda)
$$

Occasion is a predicate of SDRT's Glue Logic whose semantics involves those linguistic elements available in the logical forms of the discourse constituents that are relevant to inferring Narration. It exploits lexical semantics and shared knowledge in terms of scripts connecting certain event types in sequences in which one event 'naturally' leads to the next, though it is not the cause thereof. For instance, (8) is an example of Narration where Occasion holds, since there is clearly in the shared knowledge a script in which, before entering, people knock at the door ${ }^{7}$. This kind of knowledge is represented by AxiOM OcCASION 1.

(8) Paul frappa à la porte. Il entra.

[6] In effect, however, this added expressive power of the theory does not come at great computational cost: Baldridge et al. (2007) show that relational parsers for SDRS graphs have no greater complexity than ordinary tree parsers.

[7] Cases where Occasion does not hold may be illustrated by an example such as 
'Paul knocked at the door. He entered.'

Axiom Occasion 1

$\left(?(\alpha, \beta, \lambda) \wedge\left[\right.\right.$ frapper-à-la-porte $\left(e_{\alpha}, x\right) \wedge\left[\operatorname{entrer}\left(e_{\beta}, x\right)\right](\beta)>\operatorname{Occasion}(\alpha$, $\beta)$

We now turn to another way of inferring Narration, with a monotonic inference this time. This is when a specific discourse marker is present. In (Bras et al. 2001), it was shown that puis is such a marker - which endows it with the status of temporal connective defined in section 1. Its role in SDRT is described by the following axiom:

$$
\begin{aligned}
& \text { Axiom NARRATION PUIS }{ }^{8} \\
& (?(\alpha, \beta, \lambda) \wedge \text { [puis] }(\beta)) \rightarrow \text { Narration }(\alpha, \beta, \lambda)
\end{aligned}
$$

Last, Narration can be inferred between $\alpha$ and $\beta$ from information relevant to subsequent constituents, one of which is linked to $\beta$. An example motivating this sort of rule occurs with a simple discourse like (9):

(9) Nicholas a travaillé sur son papier, il a dîné avec Myriam et Anne, puis il est reparti pour Teilhet.

'Nicholas worked on the paper, had a meal with Myriam and Anne and then went home to Teilhet.'

The last two clauses are forcibly linked by Narration because of the discourse connective puis. But this discursive link leads us to interpret the link between the first and the second clause as one of Narration. It is this sort of situation that the following axiom on Subsequent Relations, is designed to address:

Axiom SubSequent Relations

$\left(?(\alpha, \beta, \lambda) \wedge R(\beta, \gamma, \lambda)^{\prime}\right)>R(\alpha, \beta, \lambda)$

where $R$ is any discourse relation used in SDRT.

Let us now examine the two major semantics effects of Narration on discourse content. The first one aims at capturing the fact that narratives must cohere in the sense that the events linked by Narration must fit consistently and without significant spatio-temporal gaps as expressed in (Asher et al. 1995) and (Asher 1996) and observed in earlier work on temporal order in narratives (see for example Caenepeel 1989). This doesn't mean that there should be no interval of time between the two events $e_{\alpha}$ and $e_{\beta}$, but rather that no relevant event, i.e. no event interfering with $e_{\alpha}$ or $e_{\beta}$, can occur during this interval. This constraint is for-

[8] We remark that our axiom does not of course entail that every instance of Narration can be marked by puis. In our approach, there is not equivalence between the discourse relation and the presence of the connective. 
malized in (Bras et al. 2001) by the following axiom rewritten in the notation of (Asher and Lascarides 2003): ${ }^{9}$

\section{Axiom Narration Temporal efFects \\ Narration $(\alpha, \beta) \Rightarrow e_{\alpha} \supset\left(\operatorname{post}\left(e_{\alpha}\right) \cap \operatorname{pre}\left(e_{\beta}\right)\right) \supset e_{\beta}$}

This axiom expresses a meaning constraint on Narration. It uses not the language of Glue Logic itself but the base logic in which the semantics of SDRSs is given. This language is much richer than the Glue Logic and can appeal to notions that are used traditionally in semantics, including the relation of abutment $(\supset \subset)$ used in DRT, which is equivalent to the "meets" relation as used in Allen's theory (Allen 1984), a function $\cap$ taking pairs of events into the maximum interval during which both events obtain; and the functions post-state and pre-state - the post-state of $e_{\alpha}, \operatorname{post}\left(e_{\alpha}\right)$, is a state that begins at the end of $e_{\alpha}$ and persists by default indefinitely into the future, while the pre-state of $e_{\alpha}$ is the state that terminates at the beginning of $e_{\alpha}$ and extends indefinitely far back into the past. The right hand side of the axiom expresses that $e_{\alpha}$ abuts post $\left(e_{\alpha}\right) \cap \operatorname{pre}\left(e_{\beta}\right)$ which in turn abuts $e_{\beta}$. It entails in addition that there is no intervening event whose propositional content interferes with either that of post $\left(e_{\alpha}\right)$ or that of pre $\left(e_{\beta}\right)$, i.e., no event that ends post $\left(e_{\alpha}\right)$ before $e_{\beta}$ starts or prevents $\operatorname{pre}\left(e_{\beta}\right)$ from holding right after $e_{\alpha}$ has ended $^{10}$. For illustrations, see (Bras et al. 2001), (Borillo et al. 2004).

Narration has a second semantic effect. It is motivated by the intuition that the elements of a Narration must belong to the "same story", i.e., they must have some common subject matter. To this effect, axiom Axiom NARRATION Topic expresses that the constituents held together by Narration must have a common Topic. A topic is a simple constituent which is contingent (i.e., not vacuous, not contradictory, not tautological), and subsumes the constituents of a sub-SDRS, in this case, the constituents linked by Narration. If not already present in the context, it has to be added to the SDRS during the update. Axiom NARRATion TopiC and the rules of Glue Logic actually imply that Narration can be non-monotonically inferred only if such a topic exists or can be built.

Axiom Narration Topic

$\operatorname{Narration}\left(\alpha, \beta \Rightarrow \neg \square\left(K_{\alpha} \sqcap K_{\beta}\right)\right.$

where $\sqcap$ is a merge operation defined in Asher (1993) for defining topics. The axiom states that the topic of $\alpha$ and $\beta$ cannot be vacuous, which we formalize in

[9] We will forego the use $\varphi_{R(\alpha, \beta)}$ of (Asher and Lascarides 2003) and use $R(\alpha, \beta)$ instead for ease of reading.

[10] From Axiom Narration Temporal efFects and uncontroversial ordering assumptions on events and their pre- and post-states (Event $(e) \rightarrow \operatorname{pre}(e) \supset \subset \supset \subset$ post $(e)$ ), we can deduce a relation of temporal precedence between the events $e_{\alpha}$ and $e_{\beta}: e_{\alpha} \prec e_{\beta}$, which was the original temporal effect of Narration in (Lascarides and Asher 1993). 
SDRT as a necessary truth.

To illustrate these structural effects, let us consider the simple example (8) again. This small text clearly tells the story of Paul arriving at someone's home or office. Such a "topic" is inferred only because the two sentences are textually linked together and in this order.

\section{[2.3] The Discourse Relation of Result}

Result can be non-monotonically inferred on the basis of lexical semantics or of some shared knowledge on the types of eventualities in $\alpha$ and $\beta$ as in (10):

Tarzan poussa Jane. Elle tomba.

'Tarzan pushed Jane. She fell.'

For this example, some information that generalizes on the event types of pushing and falling suggests to the reader a causal link that the narrator most likely wants to express. The presence of such clues indicating a possible causal link is expressed by the predicate Cause $_{D}$ where Cause $_{D}(\alpha, \beta)$ means that $\alpha$ describes an eventuality which is a possible cause for $\beta$ 's main eventuality ${ }^{11}$. For instance, the following axiom encodes a plausible piece of shared knowledge:

$$
\begin{aligned}
& \text { AxIOM CAUSE }_{\mathrm{D}} 1 \\
& \left(?(\alpha, \beta, \lambda) \wedge\left[\text { change_of_force }\left(e_{\alpha}, x, y\right)\right](\alpha) \wedge\left[\text { change_of_position }\left(e_{\beta}, y\right)\right]\right. \\
& (\beta)) \rightarrow \text { Cause }_{\mathrm{D}}(\alpha, \beta)
\end{aligned}
$$

SDRT relies on a lexicon to infer that pousser $\left(e_{\alpha}, x, y\right)$ is an instance of change_of_fo$r c e\left(e_{\alpha}, x, y\right)$ and that tomber $\left(e_{\beta}, y\right)$ is an instance of change_of $f_{-}$position $\left(e_{\beta}, y\right)$ in order to deduce that Cause $_{D}(\alpha, \beta)$ holds in this particular case. SDRT then allows us to deduce the discourse relation Result when one can infer the predicate Cause $_{D}$ (we simplify the axiom of Asher and Lascarides (2003) as we will not consider different aspectual classes):

\section{Axiom Result$$
\left(?(\alpha, \beta, \lambda) \wedge \text { Cause }_{\mathrm{D}}(\alpha, \beta)\right)>\operatorname{Result}(\alpha, \beta, \lambda)
$$

A Result relation between constituents $\alpha$ and $\beta$ represents the narrator's intention to signify that $\beta$ is a result of $\alpha$ (or $\alpha$ results in $\beta$ ). It has the semantic effect of implying a causal link between the main eventualities of the constituents it relates, which we write using the formalism of Asher and Lascarides (2003) as follows:

[11] The causal link expressed by Cause $_{D}$ is neither entailing nor being entailed by Occasion. We remind the reader that Occasion and Cause $e_{D}$ are not Discourse Relations but predicates specifying information from a variety of knowledge sources leading to the inference of the Discourse Relation at stake: Narration or Result. 


\section{Axiom Result Semantic-Effects \\ $\operatorname{Result}(\alpha, \beta) \Rightarrow \operatorname{Cause}\left(e_{\alpha}, e_{\beta}\right)$}

The predicate Cause $\left(e_{\alpha}, e_{\beta}\right)$, to be read $e_{\alpha}$ causes $e_{\beta}$, implies, among other things, that if $e_{\alpha}$ and $e_{\beta}$ are events, the first temporally precedes the second $e_{\alpha} \prec e_{\beta}$.

Asher and Lascarides (2003) don't give any explicit marker of Result, as we did above for Narration with puis. We mention that puis, together with the explicit marking of Narration, is a kind of "negative clue" for Result, as it blocks the inference of this relation (Bras et al. 2001) ${ }^{12}$ :

Axiom Result puis

$(?(\alpha, \beta, \lambda) \wedge[$ puis $](\beta))>\neg$ Result $(\alpha, \beta, \lambda)$

It was also suggested in (Bras et al. 2001) that Result may be monotonically inferred on the basis of the presence in $\beta$ of an explicit marker of causation, such as the conjunct donc (therefore):

(11) Max a eu son bac. Donc il a pu entrer à l'université.

'Max passed his A-levels. Therefore he could go to the university.'

But donc has other meanings, which do not express a "material" consequence, but rather a logical or argumentative consequence, which contradicts the temporal counterpart of Cause, as in:

(12) Il a réussi à faire l'exercice, donc il a bien compris le cours.

'He succeeded in solving the problem, therefore he understood the class well.'

As a matter of fact, in order to define an axiom such as AXIOM NARRATION PUIS, we need a detailed study of the lexical marker. Such an analysis for alors is spelled out in the next section.

\section{[3] alors AS A TEMPORAL CONNECTIVE}

\section{[3.1] Formalization in extant SDRT}

In this section we specify which extant discourse relations of SDRT are able to express the consequential value necessarily involved by alors when it plays the role of a temporal connective.

[12] For instance, the reading we get in an example such as

(i) L'acide tomba dans le liquide. Puis une explosion se produisit.

'The acid fell into the liquid. Puis an explosion happened.'

is one in which the author does not commit himself regarding a possible causal relationship between the events and tries to objectively tell the story of what happened during the chemical experiment. 
Let us first examine example (4) repeated below:

(4) Olivier a fait tomber la carafe. Alors elle s'est cassée.

According to the AxIOM Result given above, SDRT predicts a discourse relation of Result between the two constituents described by example (4): the information needed to infer Cause $_{D}$ is readily available - tomber $(x)$ is a permissible cause of se casser $(x)$. Although SDRT does not specify sentence initial alors as a discourse marker of Result to draw this inference, sentence initial alors in this case would not block the inference but rather lead to the same conclusion. However, in real texts, it is difficult to find examples similar to (4), and in any case, (4) itself is not an example of perfectly idiomatic French. Alors doesn't appear to fit in contexts where the Cause $_{D}$ predicate expresses an "objective" causal link, such as the one conveyed by (4). Actually, the kind of attested examples with alors where Result can be inferred thanks to Cause $_{D}$ are cases where the causal link is more "subjective", as in (13) and (14) below ${ }^{13}$ :

(13) Mme Couze a dit d'abord qu'on ne te voyait plus jamais et que ces messieurs $\mathrm{du}$ restaurant devaient te regretter. Alors Mme Londe a répondu: Une de perdue, dix de retrouvées. (Julien Green, Léviathan).

'Mme Couze first said that we never saw you any more and that the gentlemen at the restaurant must miss you. Alors Mme Londe responded: one lost, but ten found.'

(14) Il fit ses comptes et s'aperçut qu'il avait tant donné de traites au porteur, qu'il ne lui restait plus que cinquante mille francs. Alors il se fit en lui une réaction étrange: lui qui venait d'abandonner cinq millions, il essaya de sauver les cinquante mille francs qui lui restaient. (Alexandre Dumas père, Le Comte de Monte-Christo)

'He did the books and then noticed that he had given so much to the porter that he only had 50000 francs left. Alors he had a strange reaction: he who had just lost five million now tried to save the 50000 francs that he still had.'

Examples (13) and (14) are clear cases of the Response relation, along the lines of Sandström $(1993,63)$ : "Response is the relation between an event $e_{1}$ and an action $e_{2}$ which it evokes in a sentient agent". In SDRT these cases are subsumed under Result because of their causal nature (Bras et al. 2001, 137). So here again, in the extant SDRT framework, Result can be inferred thanks to Cause $_{D}$ without the help of alors.

In order to understand the role of alors, it is necessary to consider examples where alors is responsible for the causal link at stake, such as in (2), repeated

[13] All our attested examples are taken from the textual database Frantext: http://www.frantext.fr. 
below, or the constructed example (15). Without the connective, (2') and (15') lack any causal link of that sort and are rather marginal examples of Narration, given a null context.

(2) Je suis allée jusqu'à la place du village, alors je l'ai vu arriver.

(15) Il m'a rejointe. Alors je me suis souvenue que j'avais oublié mes clés. 'He joined me. Alors I remembered that I had forgotten my keys.'

(2') Je suis allée jusqu'à la place du village, je l'ai vu arriver.

(15') Il m'a rejointe. Je me suis souvenue que j'avais oublié mes clés.

In the examples (16)-(18) extracted from real texts, we find evidence of this causal relation:

(16) Elle ne vit pas le télégramme. Un peu plus tard elle ressortit avec un jeu de boules de pétanque en matière plastique contenu dans une espèce d'étui à claire-voie. Alors elle vit le télégramme, le ramassa et le lut et courut vers la plage. (Jean-Patrick Manchette, Trois hommes à abattre)

'She didn't see the telegram. A little later she came out with a pair of plastic bacci balls contained in a sort of see through carrying case. Alors she saw the telegram, picked it up, read it, and ran towards the beach.'

(17) Puis les allées commencèrent de monter assez raide et, bientôt, Joseph se trouva sur le plateau. Alors Joseph leva la tête, vit le ciel et poussa un long soupir. Jamais il ne songeait à regarder le ciel. (Georges Duhamel, Chronique des Pasquier)

'At that point the streets started to climb pretty rapidly and soon Joseph found himself on top of the plateau. Alors Joseph raised his head, looked at the sky and let out a long sigh. Never did he think to look at the sky.'

(18) Je l'ai emporté dans ma chambre. Avant de l'ouvrir, je me suis assise et je l'ai posé sur mes genoux. Alors je me suis souvenue que je l'avais eu il y avait très longtemps, et que, lorsque je l'avais regardé pour la première fois, je n'étais pas dans la maison de M. Drapeur. (André Dhôtel, Le Pays où l'on n'arrive jamais)

'I brought it into my room. Before opening it, I sat down and placed it on my knees Alors I remembered that I had possessed it long long ago and that when I had gazed on it for the first time, I was not in the house of M. Drapeur.'

From a strict SDRT point of view, the requisite information needed to infer Cause $_{D}$ for (2) and (15)-(18) is lacking. For instance in (2), to infer Result we would have to assume that an event of the type "going to the village square" is normally a plausible possible cause of an event of the type "seeing someone arrive", which is 
not the case. So, with the extant SDRT axioms, we cannot infer Result.

It also seems improbable that Occasion, the relevant predicate on eventuality types needed to infer Narration, holds between the two constituents in (2) and (15)-(18), because the types of events exemplified in this text do not specify a stereotypical sequence. So the appropriate axiom Axiom NARRATION can not be used to infer Narration. As SDRT does not yet account for the role of alors, it would predict Narration thanks to the Axiom SubSEQuent Relations. However, this inference does not match our description of the role of alors: in these examples, as shown in section 1, alors triggers a discourse relation requiring that the event expressed by the first constituent is a "condition of realization" for the event described by the second constituent'. This relation differs from the extant, similar SDRT relations of Result and Narration.

\section{[3.2] Formalization within an enriched set of discourse relations}

Asher and Lascarides (2003) don't give a complete definition of Result, but they take $\operatorname{Result}(\alpha, \beta)$ to imply Cause $\left(e_{\alpha}, e_{\beta}\right)$, which means that the main eventuality in $\alpha$ "is the cause of" the main eventuality in $\beta$. Cause is not to be confused with Cause $_{D}$, it is a predicate that holds between eventualities and not eventuality types as Cause $_{D}$ does. Although Cause is not formally defined in (Asher 1993), nor in (Lascarides and Asher 1993) and (Asher and Lascarides 2003), we take it to correspond to a strong causal link between $e_{\alpha}$ and $e_{\beta}$, which we will presently define.

With this informal definition of Cause as a "is the cause of" relation, we can account for (4) and (13)-(14) correctly. For (2) and (15)-(18), a strict cause-consequence link is too strong: so we do not want to introduce an axiom stipulating that alors would imply Result (after the model of Axiom NARRATION PUIS). Alors does not trigger an inference to the discourse relation Narration either. Rather, it expresses another kind of causal link, that we described above, following Hybertie, as a "condition of realization", which we feel to be somewhere between Narration and Result.

It thus seems necessary to introduce a new relation, that should have weaker causal implications (and for which alors would be a trigger). To capture this weaker causal link, we turn to Lewis (1973) who defines several causal relations. In particular, his "causal dependency" relation is close to what we need to express, except that we will restrict our causal links to actually occurring events. Following Lewis, we define the relation Weakly_causally_depends_on:

$\mathrm{e}_{\beta}$ Weakly_causally_depends_on $\mathrm{e}_{\alpha}$ if and only if

(i) if $\mathrm{e}_{\alpha}$ had not occurred, $\mathrm{e}_{\beta}$ wouldn't have occurred either, in all the worlds closest to $\alpha$ 's world, and

(ii) (it is true that) $e_{\alpha}$ occurred and (it is true that) $e_{\beta}$ occurred.

We would like to add the requirement that $e_{\alpha}$ precedes $e_{\beta}$. Formally, we offer the 
following definition in SDRT, where we appeal to Lewis' similarity relation that he uses to define counterfactuals and where the causal relation is expressed as holding between event types or facts:

An event $e_{\beta}$ associated with a description $K_{\beta}$ (in a discourse constituent $\alpha$ ) Weakly_causally_depends_on an event $e_{\alpha}$ associated with a description $K_{\alpha}$ (in a discourse constituent $\beta$ ) if and only if $\left(\neg K_{\alpha} \square \rightarrow\right.$ $\left.\left.\neg K_{\beta}\right) \wedge\left(K_{\alpha} \wedge K_{\beta}\right) \wedge e_{\alpha} \prec e_{\beta}\right)$, where $\mathrm{A} \square \rightarrow \mathrm{B}$ is true in a world $w$ if and only if in every world closest to $w$ where $\mathrm{A}$ is true, $\mathrm{B}$ is true too.

We emphasize that "in every world closest to $w$ " means that the implication has to be considered "other things being equal", and hence defeasible. For instance, for (2), we cannot consider an event of "her climbing up on a wall". Of course that event could have been a cause for the event "her seeing him arrive", but this event occurs in a world that doesn't belong to the closest worlds to $w$.

Having defined the relation Weakly_causally_depends_on, we can formally define the stronger causal relation Causally_depends_on:

$e_{\beta}$ Causally_depends_on $e_{\beta}$ if and only if $e_{\beta}$ Weakly_causally_depends_on $e_{\alpha}$, and $K_{\alpha}>K_{\beta}$

Causally_depends_on is stronger than Weakly_causally_depends_on in a strict sense, thanks to the formula $K_{\alpha}>K_{\beta}{ }^{14}$.

Weak causal dependency and causal dependency can hold between events, but they can also hold between event descriptions or facts, elements described by constituents.

We have expressed the semantics for our two causal relations in the full SDRT language, not the description language in which the Glue Logic axioms for inferring discourse relations is stated. Thus, since we are speaking about the causal relations themselves and not about a description of the occurrence of this relation symbol in some SDRS, as we do in the Glue Logic, we have expressed our definitions using intuitive two place relations, rather than the description language three place formulas.

Our two causal relations permit us to make some distinctions at the discursive level. The first is that we introduce a new discourse relation, which we call WeakResult. As is usual, we constrain the semantics of this relation via axioms about its semantics effects:

[14] Our notion of causal dependency differs from that of (Lewis 1973) only in that we replace the counterfactual $\left(K_{\alpha} \square \rightarrow K_{\beta}\right)$ in his definition with a normality conditional and we insist that the relation hold between actually occurring events. This replacement is essential if we wish, as we do, to restrict our relations to actually occurring events, since in Lewis' logic of counterfactuals $\left(K_{\alpha} \wedge K_{\beta}\right)$ implies $\left(K_{\alpha} \square \rightarrow K_{\beta}\right)$. Thus using Lewis' definition in our case would reduce our relation of causal dependency to the relation of weak causal dependency. 
Axiom Weak-Result Semantic-EFfects

Weak-Result $(\alpha, \beta) \Rightarrow$ Weakly_causally_depends_on $\left(K_{\alpha}, K_{\beta}\right)$

This formulation of Weak-Result encodes that it entails the Weakly_causally_depends_on relation between the event descriptions in the constituents labelled with $\alpha$ and $\beta$. We use this relation to account for non purely logical cases where causes precede consequences (the logical cases will be analysed further).

Alors, as we have seen, is responsible for introducing a relation whose content is just that for Weak-Result. This means that we should introduce an axiom in the Glue Logic and its description language, expressing that alors is a trigger for Weak-Result:

Axiom WeAK Result triggering

$(?(\alpha, \beta, \lambda) \wedge[$ alors $](\beta)) \rightarrow$ Weak-Result $(\alpha, \beta, \lambda)$

This holds only for clause initial alors, according to the description in section 1 . When alors is not initial, it does not play a role at the discourse level but at the sentence level. Therefore its contribution will be taken into account with compositional semantic rules (i.e. within the constituent representation) and not with discourse rules such as AXIOM WEAK-RESULT.

Let us see how we can now account for our examples with the definition and axiom on Weak-Result given above. The relation of Weak-Result as defined is appropriate for linking the clauses in (15)-(18). For example, in (15) we have: "if he hadn't rejoined me, I wouldn't have remembered"; further, it is both true that "he rejoined me" and that "I remembered"; and finally, the event of his rejoining me precedes the event of my remembering.

On the other hand, Weak-Result is insufficient to describe the discourse link in (4) and (13)-(14): the causal link at stake is stronger than the weak causal dependency: it corresponds to the relation of causal dependency defined above. This leads us to the conclusion that Result is a scalar relation: along with Weak-Result, there is also a relation that we call Strong-Result, which can be defeasibly inferred from Cause $_{D}$, and which we define as reflecting the relation of causal dependency and the relation Causally_depends_on.

Axiom Strong-Result Semantic-effects

Strong-Result $(\alpha, \beta) \Rightarrow$ Causally_depends_on $\left(K_{\alpha}, K_{\beta}\right)$

Axiom Strong-Result triggering

$\left(?(\alpha, \beta, \lambda) \wedge\right.$ Cause $\left._{\mathrm{D}}(\alpha, \beta)\right)>$ Strong-Result $(\alpha, \beta, \lambda)$

For examples (4) and (13)-(14) both Axiom WeAK-Result and Axiom Strong-Result will apply: both Weak-Result and Strong-Result will be inferred. For the same examples without alors, Strong-Result would be inferred too. However, unlike the 
naturally occurring examples (13)-(14), (4), as we noted, is not very good, for reasons which remain to be explored. Our intuition is that the objective versus the subjective nature of the causality should be taken into account (some hints in this sense are also given by Hybertie 1996).

We note that our constraints are also compatible with what we have said about puis. Puis signals that we should normally not infer Result. AхіOM Result PUIS given above should be replaced by the two following axioms:

Axiom Weak-Result puis

$(?(\alpha, \beta, \lambda) \wedge$ [puis] $(\beta))>\neg$ Weak-Result $(\alpha, \beta, \lambda)$

AXIom Strong-Result PUis

$(?(\alpha, \beta, \lambda) \wedge[$ puis $](\beta))>\neg$ Strong-Result $(\alpha, \beta, \lambda)$

This will be consistent with the fact that events in the world be linked via causal dependency or weak causal dependency, as long as these relations cannot be inferred from the information present in the discourse and the context.

We finally examine cases when alors combines with Occasion, as in (19):

Pierre est tombé. Alors je l'ai aidé à se relever.

'Peter fell. Alors I helped him up.'

In such a case, the extant axioms lead to infer Narration and Weak-Result. The conjunction of these two relations strengthens the discourse connection between the two constituents. (19) is a constructed example, but there are many examples in real texts with a similar interpretation:

(20) L'empereur se tourna à demi, avec un léger hochement de tête, pour autoriser le ministre de l'intérieur à continuer. Alors Rougon entra dans des détails préliminaires. (Émile Zola, Son Excellence Eugène Rougon)

'The emperor turned around halfway with a slight nod of the head, signalling to the interior minister to continue. Alors Rougon began to lay out the preliminary details.'

(21) La grille l'attira. Il serra les barreaux rouillés très fort, comme un prisonnier. Il y appuya son front pour sentir le froid du métal. La porte s'ouvrit. Alors, il entra. (Robert Sabatier, Les Noisettes sauvages)

'The ironwork attracted him. He clasped the rusted bars very strongly, like a prisoner. He put his forehead to the metal to feel its cold. The door opened. Alors he entered.'

The combination of Occasion and alors would always seem to yield a coherent discourse in SDRT's terms. That is, they suffice to infer a discourse relation between two constituents with this information. However, this is not the case. Let us for 
instance compare (19) with (22):

(22) ?Pierre est tombé. Alors il s'est relevé.

'?Peter fell. Alors he stood up.'

Our intuition is that alors better combines with Occasion when there is a change of subject as in (19), which is similar, on that point, to (20) and (21). The contrast between (23) and (24) reinforces this hypothesis. Finally the contrast between (24) and (25) illustrates the fact that puis is particularly felicitous in the configuration of Occasion with a same subject (Bras et al. 2001, 128-129).

(23) Ils se mirent à table. Alors Pierre souhaita bon appétit à tout le monde. 'They sat down to table. Alors Pierre wished 'bon appetit' to everyone.'

(24) ?Ils se mirent à table. Alors ils se souhaitèrent bon appétit.

'They sat down to table. Alors they wished 'bon appetit' to everyone.'

(25) Ils se mirent à table. Puis ils se souhaitèrent bon appétit.

'They sat down to table. Puis they wished 'bon appetit' to everyone.'

We won't try to axiomatize here the prediction of the compatibility between alors and Occasion, as this would require a more fine-grained description of Occasion, taking the change of subject into account ${ }^{15}$. We leave this matter at this stage.

\section{[4] alors AS A LOGICAL CONNECTIVE}

In the cases we have examined so far, alors is a temporal connective, in the sense defined in section 1 . We also want to account for cases in which alors plays the role of a logical consequence connective. This logical role of alors is more frequent in discourses describing states, as in (5) and (6) repeated below:

(5) Les volets sont fermés, alors ils sont partis.

(6) Ce nombre est égal à 4. Alors il est pair.

As said above, in this paper, we restrict ourselves to events. But in fact we can also have events in discourses where alors expresses a logical consequence:

[15] Taking the change of subject into account would help make more precise the frontier between Occasion and Cause $_{D}$, as Occasion with a change of subject is often very close to Cause $e_{D}$. If we take the example of Occasion mentioned in section 3, (8), we notice that adding alors does not yield a felicitous discourse:

(8') ?Pierre frappa à la porte. Alors il entra.

Now if we modify ( $\left.8^{\prime}\right)$ by introducing a change of subject:

(8") Pierre frappa à la porte. Alors Marie lui ouvrit.

we have difficulties in classifying the event type predicate at stake between Occasion and Cause $e_{D}$. 
(26) Toutes les filles sont arrivées à l'heure, alors Marie est arrivée à l'heure.

'All the girls arrived on time, alors Marie arrived on time.'

In order to account for these cases, we introduce a discourse relation, Inferential result, expressing the logical link at stake:

Axiom Inferential-Result Semantic-Effects

Inferential-Result $(\alpha, \beta) \Rightarrow\left(K_{\alpha} \wedge K_{\beta} \wedge\left(K_{\alpha}>K_{\beta}\right)\right)$

Actually, in cases like (6) and (26) we have $\square\left(K_{\alpha} \rightarrow K_{\beta}\right) . K_{\alpha}>K_{\beta}$ is meant for cases like (5). Insofar as $\square\left(K_{\alpha} \rightarrow K_{\beta}\right)$ implies $K_{\alpha}>K_{\beta}$ both cases fit our definition. Further research will have to include the analysis of inferential result involving states and will probably lead to a refined formalization.

We see now that alors can trigger both Weak-Result and Inferential-Result. Since Inferential-Result is triggered relative to information that entails the information used to infer Weak-Result, we rewrite our AхIOM WeAK-Result, changing the monotonic axiom for a non-monotonic one:

\section{AxIOM WeAK-Result 2 \\ $(?(\alpha, \beta, \lambda) \wedge[$ alors $](\beta))>$ Weak-Result $(\alpha, \beta, \lambda)$}

This allows us to introduce a more specific axiom to trigger Inferential-Result.

Axiom InfEREnTIAL-REsult Triggering

(? $(\alpha, \beta, \lambda) \wedge[$ alors $](\beta) \wedge \neg$ Weakly_causally_depends_on $\left.\left(K_{\alpha}, K_{\beta}\right)\right)>$ Inferential-Result $(\alpha, \beta, \lambda)$

Let us illustrate the application of these axioms for (26). With Axiom WeAKResult 2 we infer Weak-Result $\left(\pi_{1}, \pi_{2}\right)$. But Weak-Result $\left(\pi_{1}, \pi_{2}\right)$ does not hold because the temporal constraint $e_{1} \prec e_{2}$ is wrong. The temporal relation is $e_{2} \subseteq e_{1}$, as obtained by the following reasoning: the proper noun Marie in $K_{2}$ triggers the presupposition of existence of a girl named Marie. We can bind this presupposition if we can infer that this referent is part of the plural referent in the universe of $K_{1}$ thanks to the semantics of the quantifier toutes les filles. As we have the same event types for $e_{1}$ and $e_{2}$, and the subject referent of $e_{2}$ being a part of the subject referent of $e_{1}$, we infer that the event of Marie arriving on time $\left(e_{2}\right)$ is part of the event of all the girls arriving on time $\left(e_{1}\right)$. As the binding of a presupposition is preferred to accommodation in standard theories of presupposition (Van der Sandt 1992) as well as in SDRT (Asher and Lascarides 2003), we are forced to this treatment of the presupposition and to the inference concerning the temporal relation between $e_{1}$ and $e_{2}$. This means that Weak-Result cannot apply, and by Axiom InfERENTIAL- 
Result TRIGgering ${ }^{16}$, we conclude Inferential-Result.

Our investigation concerning the discourse information conveyed by sentence initial alors has revealed at least three sorts of relations close to the informal gloss given by Asher (1993) and Asher and Lascarides (2003) for Result. We have seen that alors alone suggests a weak causal relation, which we have formalized using Lewis' counterfactual. We encoded this information in the discourse relation Weak-Result, which we distinguished from Strong-Result. Strong-Result is inferred when lexical or other contextual information triggers a causal, discursive link. Our definitions immediately imply that both Strong-Result and WeakResult are veridical relations in the sense of Asher and Lascarides (2003). We also saw that alors can, when Weak-Result is blocked, suggest an inferential relation, which we expressed using the weak conditional > already present in the SDRT formalism.

Our analysis of the discursive uses of alors in initial position with clauses that involve events paints a uniform but complex picture of this discourse connective. In future work we intend to extend this study to treat uses of alors that involve reference to states. Our proposal to analyse Result as a scalar relation should now be put to the test and refined through a systematic comparison of alors with other discourse connectives also related to causality such as donc, du coup or de ce fait (cf. Rossari and Jayez 1996, 2000).

[16] Inferential-Result differs from the SDRT relation called Defeasible-Consequence, used to express conditionals, which is not veridical. It would be interesting, as one of our reviewers suggests, to compare our treatment of Inferential-Result as triggered by alors with the relation triggered by donc: donc does not embed within conditionals, while alors does. While we have not yet studied the role of alors within conditionals, and we have not studied donc either, we can offer some suggestions as to how these connectives might differ. The semantics for alors that we have given, as well as the general architecture of SDRT, does not preclude the embedding of alors within a conditional; when this occurs, this means that two relations hold between the antecedent and the consequent of the conditional, the one specified by alors and the one specified by the conditional. There is, however, a clash between these two relations: the conditional does not imply a veridical relation between antecedent and consequent, whereas alors does. But notice that alors is naturally understood as occurring within the scope of the conditional; this means that we should interpret alors as contributing material to the consequent of the conditional, specifying, as it were, the relation between antecedent and consequent. Interpreted in this way, there is no clash; the consequent is to be interpreted on the assumption that the antecedent is true, and so the veridicality of the discourse relation contributed by alors is no longer problematic. None of this tells us why donc cannot be used within the scope of a conditional. One hypothesis worth exploring, however, is that donc introduces the same relation as the conditional, plus the constraint that its terms be true. This is, donc would have a similar analysis to alors, except that instead of allowing us to infer Weak-Result or Inferential-Result, it leads to the inference of a consequence relation, exactly the relation introduced by the conditional. Some preliminary evidence that this is so comes from the observation that the deduction theorem of classical logic seems to hold with donc : A, donc B seems to be equivalent to Si A, B. This does not seem to be the case with alors. If this analysis is on the right track, then we would have at least a pragmatic explanation for why si $A$ donc $B$ is not very good: donc at this point is redundant. 
REFERENCES

Allen, J. A. 1984. Towards a General Theory of Action and Time. Artificial Intelligence 23, 123-154.

Asher, N. 1993. Reference to Abstract Objects in Discourse. Dordrecht: Kluwer.

Asher, N. 1996. Mathematical Treatments of Discourse Contexts. In Proceedings of the 10th Amsterdam Conference on Formal Semantics, volume 1, pages 21-40, ILLC Publications, Amsterdam.

Asher, N., Aurnague, M., Bras, M., Sablayrolles, P. and Vieu, L. 1995. De l'espacetemps dans l'analyse du discours. Sémiotiques 9, 11-62.

Asher, N. and Lascarides, A. 2003. Logics of Conversation. Cambridge: Cambridge University Press.

Asher, N. and Morreau, M. 1991. Commonsense Entailment: A Modal Theory of Nonmonotonic Reasoning. In J. Mylopoulos and R. Reiter (eds.), Proceedings of the Twelfth IJCAI, pages 387-392, Los Altos, CA.: Morgan Kaufman.

Asher, N. and Vieu, L. 2005. Subordinating and Coordinating Discourse Relations. Lingua 115(4), 591-610.

Baldridge, J., Asher, N. and Hunter, J. 2007. Annotation for and Robust Parsing of Discourse Structure on Unrestricted Texts. Zeitschrift für Sprachwissenschaft 26(2), 213-239.

Borillo, A., Bras, M., De Swart, H., Le Draoulec, A., Molendijk, A., Verkuyl, H., Vet, C., Vetters, C. and Vieu, L. 2004. Tense and Aspect. In F. Corblin and H. de Swart (eds.), Handbook of French Semantics, pages 233-348, Stanford: CSLI Publications.

Bras, M., Le Draoulec, A. and Vieu, L. 2001. French Adverbial Puis between Temporal Structure and Discourse Structure. In M. Bras and L. Vieu (eds.), Semantic and Pragmatic Issues in Discourse and Dialogue: Experimenting with Current Theories, CRiSPI series,, volume 9, pages 109-146, Amsterdam: Elsevier.

Caenepeel, M. 1989. Aspect, Temporal Ordering and Perspective in Narrative Fiction. Ph. D.thesis, University of Edinburgh, Edinburgh.

Franckel, J. J. 1987. Alors, alors que. Bulag 13, 17-49.

Gerecht, M.-J. 1987. Alors: opérateur temporel, connecteur argumentatif et marqueur de discours. Cahiers de linguistique française 8, 69-79.

Hybertie, C. 1996. La conséquence en français. Paris-Gap: Ophrys. 
Jayez, J. 1981. Etude des rapports entre l'argumentation et certains adverbes français. Masters Thesis, Aix-Marseille 2.

Jayez, J. 1988a. L'inférence en langue naturelle. Paris: Hermès.

Jayez, J. 1988b. Alors, descriptions et paramètres. Cahiers de Linguistique Française $9,135-175$.

Kamp, H. and Reyle, U. 1993. From Discourse to Logic. Dordrecht: Kluwer.

Lascarides, A. and Asher, N. 1993. Temporal Interpretation, Discourse Relations, and Commonsense Entailment. Linguistics and Philosophy 16(5), 437-493.

Le Draoulec, A. and Bras, M. 2006. Quelques candidats au statut de connecteur temporel. Cahiers de Grammaire 30, 219-237.

Le Draoulec, A. and Bras, M. 2007. Alors as a possible Temporal Connective in Discourse. Cahiers Chronos 17, 81-94.

Lewis, D. 1973. Causation. Journal of Philosophy 70, 556-567, reprinted in Lewis, 1986, Philosophical Papers II. Oxford: Oxford University Press. 159-213.

Mann, W. C. and Thompson, S. A. 1988. Rhetorical Structure Theory: A Theory of Text Organization. Text 8:3 8(3), 243-281.

Reyle, U.1998. A note on enumerations and the semantics of puis and alors. Cahiers de Grammaire 23, 67-79.

Rossari, C. and Jayez, J. 1996. Donc et les consécutifs: des systèmes de contraintes différentiels. Lingvisticae investigationes 20(1), 117-143.

Rossari, C. and Jayez, J. 2000. Du coup et les connecteurs de conséquence dans une perspective dynamique. Lingvisticae investigationes 23(2), 303-326.

Sandström, G. 1993. When-clauses and the temporal interpretation of narrative discourse. Ph. D.thesis, University of Umeå.

Van der Sandt, R. A. 1992. Presupposition projection as anaphor resolution. Journal of Semantics 9(4), 333-378. 
AUTHOR CONTACT INFORMATION

Myriam Bras

University of Toulouse

CLLE-ERSS UMR 5263

Maison de la Recherche \&

Université Toulouse Le Mirail

5 allées Antonio Machado

F-31058 Toulouse Cedex 09

France

bras@univ-tlse2.fr

Anne Le Draoulec

University of Toulouse

CLLE-ERSS UMR 5263

Maison de la Recherche \&

Université Toulouse Le Mirail

5 allées Antonio Machado

F-31058 Toulouse Cedex 09

France

draoulec@univ-tlse2.fr

Nicolas Asher

University of Toulouse

IRIT UMR 5505 \&

Université Paul Sabatier

118 Route de Narbonne

31062 Toulouse Cedex 09

France

asher@irit.fr 